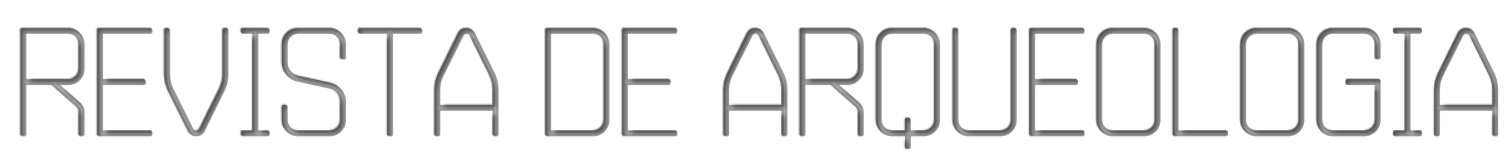

Volume 34 No.1 Janeiro-Abril 2021

\title{
SITUAÇÃO GEOMORFOLÓGICA DOS SÍTIOS ARQUEOLÓGICOS \\ NO MUNICÍPIO DE CAMALAÚ - PARAÍBA
}

Carlos Xavier de Azevedo Netto*, Conrad Rodrigues Rosa**, Thiago Fonseca de Souza***

\section{RESUMO}

O meio físico nos permite compreender a paisagem e as formas, processos de ocupação de grupos pretéritos. Na perspectiva da Geoarqueologia, o ser humano apreende o espaço conforme o uso do meio físico modificando-o, com a adaptação e processos de manufatura de instrumentos a e formação de sítios, o que implica em transformação e transição cultural. O artigo organiza informações dos assentamentos pré-coloniais de Camalaú. Metodologia de caracterização geoarqueológica, elaboração de SIG e execução de cartas temáticas. Possibilita perceber as estratégias de ocupações, que levam em consideração as formas de relevo e a posição geográfica em relação ao Norte magnético. Essas escolham permitem a compreensão das estratégias de ocupações pré-coloniais nos Cariris Velhos.

Palavras-chave: sítios arqueológicos; Geoarqueologia; pré-colonial.

* Arqueólogo, Doutor em Ciência da Informação, docente do PPGA (Antropologia) e do PPGCI (Ciência da Informação), Universidade Federal da Paraíba, Bolsista de Produtividade de Pesquisa do CNPq. E-mail: xaviernetto@gmail.com. ORCID: https://orcid.org/0000-0001-6105-3518.

** Geógrafo, Doutor em Geotecnia, pesquisador do NDIHR/LAB/UFPB, atuando na área de Geoarqueologia. E-mail: conradrosa@gmail.com. ORCID: https://orcid.org/0000-0002-0084-5578.

*** Arqueólogo e Historiador, Doutor em Arqueologia pela UFPE e pesquisador/colaborador do NDIHR/LAB/UFPB. E-mail: fonseca.pb.jp@gmail.com. ORCID: http://orcid.org/0000-0003-0374$\underline{6396 .}$ 


\section{THE GEOMORPHOLOGICAL SITUATION THE ARCHAEOLOGICAL SITES IN CAMALAU MUNICIPALITY, PARAIBA}

\section{ABSTRACT}

The physical environment allows us to understand the landscape and the forms, processes of occupation of past groups. From the perspective of Geoarchaeology, the human being apprehends the space according to the use of the physical environment; modifying it with the adaptation and manufacturing processes of instruments and the formation of sites, which implies cultural transformation and transition. The article organizes information on the pre-colonial settlements in Camalaú. The methodology of geoarchaeological characterization, elaboration of GIS, and execution of thematic maps permit us to recognize the occupation strategies, which take into account the landforms and the geographical position in relation to the magnetic North. These choices allow the understanding of precolonial occupation strategies in the Cariris Velhos.

Keywords: archaeological sites; Geoarchaeology; pre-colonial.

\section{SITUACIÓN GEOMORFOLÓGICA DE LOS SITIOS ARQUEOLÓGICOS EN EL MUNICIPIO DE CAMALAU, PARAÍBA}

\section{RESUMEN}

El entorno físico nos permite comprender el paisaje y las formas, los procesos de ocupación de grupos pasados. Desde la perspectiva de la Geoarqueología, el ser humano aprehende el espacio de acuerdo al uso del entorno físico, modificándolo, con los procesos de adaptación y fabricación de instrumentos y la formación de sitios, lo que implica transformación y transición cultural. El artículo organiza información sobre los asentamientos precoloniales en Camalaú: metodología de caracterización geoarqueológica, elaboración de SIG y ejecución de mapas temáticos. Permite comprender las estrategias de ocupación, que tienen en cuenta las formas de relieve y la posición geográfica en relación con el norte magnético. Estas opciones permiten comprender las estrategias de ocupación precoloniales en Cariris Velhos.

Palabras clave: sitios arqueológicos; Geoarqueología; precolonial. 


\section{INTRODUÇÃO}

O município de Camalaú, na Região do Cariri Paraibano, está submetido às ações naturais climáticas (intemperismo, regime pluviométrico, insolação etc), geomorfológicas e geológicas; e também às ações antrópicas (desmatamento, desvio/retenção de cursos d'água entre outros). As ações naturais provocam constantes modificações físicas, advindas do intemperismo físico, químico, biológico, processos de erosão do solo e desplacamentos da rocha matriz (maciço ígneo), alterando o ambiente de maneira significativa.

É nesse ambiente climático e geomorfológico que estão localizados diversos sítios arqueológicos na Paraíba, totalizando até o momento 16 unidades, caracterizados pelo tipo de vestígios encontrados (ossos humanos e de pequenos roedores, cerâmica précolonial, registros rupestres e líticos). Sobre o aspecto de cronologia para a região do Cariri Paraibano, com as duas datas obtidas nos municípios de São João do Cariri, e de Camalaú, ambas sobre material ósseo humano, como será visto mais adiante, sua ocupação está, até o momento, entre 1.000 e 2.000 anos antes do presente, embora Martin (2008) coloque que essas populações estariam na região até 5.000 anos antes do presente.

Considerando o ambiente físico como locus de existência de grupos humanos, onde os vestígios são o resultado da ocupação pretérita, Azevedo Netto et al. (2012, p. 1) assevera que "fenômenos ambientais vêm ganhando uma atenção especial nos mais variados estudos realizados no meio acadêmico, devido à busca de um maior entendimento das relações destes elementos com a sociedade em que neles estiveram inseridas". De modo que a situação ambiental na atualidade apresenta também vestígios de um comportamento de mudanças físicas, ou, como apresentam Ab'Saber (1969) e Suguio (2000), os processos morfoclimáticos sucessivos modelam a paisagem e criam feições residuais e feições deposicionais, ou seja, a natureza ao se modificar deixa registros na paisagem.

Assim sendo, o meio físico e o paleoambiente nos permitem compreender a paisagem e as formas e processos de ocupação de grupos pretéritos e sua relação com o meio (BINFORD, 1965; STEIN, 2001; GOLDBERG et al., 2009). Ou, como adverte Honorato (2009, p. 131), a partir de geoindicadores que "são dados do meio físico e biótico que possuem relevância para os sistemas regionais de povoamento e indicam locais de assentamentos antigos" e que estão interligados com as formas que grupos humanos interagiram entre si e com o meio. Para Goldberg et al. (2009) a perspectiva da geoarqueologia é também compreender como o ser humano apreende o espaço a partir do uso do meio físico e assim modificando-o, sendo essa modificação feita a partir da adaptação e processos de manufatura de instrumentos e formação de sítios, o que implica em processos de transformação e transição cultural.

Nesse ponto, surge o seguinte questionamento: as informações referentes à distribuição dos assentamentos pré-coloniais no município de Camalaú, Paraíba, estão correlacionadas aos processos e formas geomorfológicas?

Esta pesquisa de cunho quantitativo e qualitativo tem como objetivo organizar as informações referentes à distribuição dos assentamentos pré-coloniais no município de Camalaú, Paraíba, correlacionando-os com os processos e formas geomorfológicas. Estão inseridos nos projetos os agenciamentos semióticos na construção dos painéis rupestres, a saber, a dinâmica entre os grafismos reconhecíveis e puros, no Cariri Ocidental Paraibano (Edital Universal do CNPq), e os agenciamentos sígnicos no Cariri Ocidental. Consideramos, ainda, a dinâmica entre os grafismos rupestres e demais componentes do registro arqueológico (Edital Universal do $\mathrm{CNPq}$ ) delimitando um recorte espacial e temporal para compreender não só o ambiente, mas também a ocupação e dispersão dos grupos através da mudança ambiental e dos vestígios encontrados. 
Após essas indicações, empreendemos um estudo geoarqueológico tomando como foco o Cariri Paraibano, onde foram observadas duas datações em sítios cemitérios: uma para o sítio Barra no Município de Camalaú, de $1220 \pm 30$ anos AP (Beta 400646), realizada sobre material ósseo humano e de sepultamentos depositados em um abrigo sob rocha com a ocorrência de vários sepultamentos humanos acompanhados de cestarias, trançados de algodão e restos vegetais, cerâmica e material lítico lascado e seixos, ambos em quartzo e algumas lascas de calcedônia; outra para o sítio Serrote da Macambira, no Município de São João do Cariri, de $1880 \pm 30$ anos AP (Beta 400647), também um sítio em abrigo sob rocha, com o sepultamento de 15 indivíduos, adultos e crianças, com evidências de sepultamento secundário, revolvidos por curiosos e vândalos. No entanto, a pouca quantidade de pesquisas desenvolvidas na região deixa uma lacuna tanto cronológica quanto ocupacional.

Neste estudo, pensamos a correlação dos processos e das formas geomorfológicas como uma possibilidade de percepção em um tempo onde há o predomínio das imagens funcionado como códice à espera de seu entendimento.

\section{SITUAÇÃO GEOMORFOLÓGICA E A RELAÇÃO DOS SITIOS ARQUEOLÓGICOS COM AS FORMAS DE RELEVO}

No contexto atual das pesquisas em arqueologia, o campo geológico e geomorfológico destaca-se no que diz respeito a análises e descrição de solos, de formas de relevo e maciços rochosos, como delimitadores e indicadores na forma de apropriação do espaço e adaptação cultural (LUCENA, 1986; SANTOS, 1997; STEIN, 2001; ANGELUCCI, 2003; RUBIN; SILVA, 2004; CORREA; SILVA, 2005; BUTZER, 2008).

Nessa relação interdisciplinar, aparece a temática da Geoarqueologia que se torna elemento primordial como balizador da investigação das interações entre o ambiente natural e ambiente antropizado. Como assevera Lucena (1986), a ação humana interfere no ambiente pretérito desencadeando processos de alteração nas camadas estratigráficas. Para Stein (2001), a ação antrópica é uma atividade participativa no meio, alterando aspectos naturais ao serem formados os sítios, visto que essa ação induz em uma modificação externa, seja a partir de sepultamentos, indústria lítica, ou simplesmente se apropriando do ambiente. Nesse sentido, é importante compreender as áreas de conhecimento que circundam a disciplina da geoarqueologia, os conceitos do meio físico geológico e geomorfológico, bem como os processos de intemperismo que ocorrem na área de estudo.

Para uma melhor compreensão do meio físico, Mabesoone e Lobo (1980) apresentam as fases da formação dos processos de erosão e deposição que se inicia no Pleistoceno na Superfície Sertaneja, ou seja, processos de denudação superficial nos Cariris Velhos originando a formação de solos nessa região. A perspectiva dada pelos autores é de orientar pesquisas no âmbito das geociências e compreender que esse ambiente favorece a atuação de elementos contracionais, bem como processos intempéricos que formam as vertentes e áreas de rocha exposta (afloramentos) (BRITO NEVES et al., 1995). Christofoletti (1980) apresenta que vertente é um processo de denudação que ocorre entre o interflúvio e o fundo de vale, que traz o conceito de planos de declives entre o ponto mais alto ao mais baixo formando o vale.

É importante observar o relevo de um modo geral, além das formas de relevo tipificadas. Como apregoa Casseti (1981, p. 55), "o relevo é caracterizado, de modo geral, por superfícies erosivas, pediplanadas, formas de dissecação, como as tabulares, convexas e aguçadas, podendo apresentar variações ou combinações numa área restrita”. Essa perspectiva contribui aos estudos da geoarqueologia nas observações de ocupação 
humana sobre o relevo onde o homem apreende as formas de relevo para nela se assentarem (MORAIS, 2000; DEL LAMA, 2006; HONORATO, 2009).

Santos (1997) assevera que a geomorfologia é uma disciplina de suma importância para os estudos arqueológicos, pois a partir do entendimento das formas de relevo é possível elaborar hipóteses de assentamento, uso e ocupação do espaço pré-histórico. $\mathrm{Na}$ compreensão do ser humano como agente modificador da paisagem e, portanto, do relevo, como observa Suguio (2000, p. 81), "o homem é durante o Holoceno o agente geológico e/ ou ecológico". Ou ainda, como entende Ingold (2012), a paisagem é apreendida e composta pelos habitantes, humanos e não-humanos, a partir do processo de perceber as coisas e seus processos formativos, tornando-se partícipe dessa formação, em que as suas interações configuram-se como uma malha.

A discussão sobre paisagem no contexto geoarqueológico é importante, podendose afirmar que a junção dos conceitos de arqueologia e geociências (MORAIS, 2000; HONORATO, 2009) formam a arqueologia da paisagem. Morais (2000) assevera que os fatores de ordem ambiental colaboram para a compreensão dos padrões de estabelecimento para a caracterização socioeconômica e cultural dos grupos.

Descrever a geologia e geomorfologia em um trabalho arqueológico é descrever e explicar a ocupação do espaço sob a perspectiva de geoindicadores (HONORATO, 2009; SOUZA, 2016); é compreender os maciços geológicos, os abrigos de rocha, as unidades de relevo, a hidrografia. Enfim, os conjuntos do geossistema, território e paisagem nos levam a inferir na relação entre os assentamentos e o meio natural.

Ao se utilizar da definição de Geoarqueologia - disciplina que inter-relaciona tópicos de Geociências, Ocupação Humana e Vestígios Arqueológicos. Angelucci (2003) explica as formas físicas sob a ótica da ocupação pretérita, ou seja, como e porque determinadas localidades foram habitadas. Trata-se de argumentos hipotéticos, mas Angelucci (2003, p. 42) apresenta uma explicação:

Uma das bases conceptuais de qualquer geoarqueólogo reside na convicção que as dinâmicas culturais podem ser reconstituídas, ou seja, que as comunidades humanas actuaram e actuam através de processos que são legíveis e interpretáveis com conceitos "geo". Por outras palavras, que os humanos deixam, do ponto de vista dos processos e das dinâmicas com que agem, "assinaturas" que, oportunamente lidas, permitam realizar uma reconstituição comportamental e cultural das comunidades humanas do passado.

A partir do argumento supracitado, procedemos à leitura do meio físico fixando nosso olhar nos dados da ocupação, dos assentamentos e da alteração ocasionada no ambiente, partindo do entendimento de Cassirer (1977), de que o homem está imerso em um universo simbólico que ele construiu e onde extrapola o espaço de sua experiência imediata. Ou, como assegura Ingold (2012), não se pode abordar a natureza fora das relações simbólicas, pois as mesmas configuram o relacionamento dos indivíduos com o ambiente. Assim,

abdicar desse caráter simbólico do comportamento humano é abrir mão de compreender como as escolhas foram realizadas, de compreender por que tais abrigos receberam pinturas e não outros, porque os sepultamentos foram realizados naquele sítio e não em outros. (ISNARDIS; LINKE, 2010, p. 44)

O universo que o estudo arqueológico trabalha é de natureza simbólica, pois os ambientes que os grupos humanos habitavam não são definidos somente em função da sua sobrevivência, pelo contrário, as escolhas desses ambientes são ideológicas e simbólicas (BINFORD, 1965). Portanto, para compreender a intrínseca relação entre o homem e a natureza, que é mediada por uma dimensão simbólica, há que se debruçar no 
estabelecimento das informações obtidas nas áreas arqueológicas a partir da cultura material (os artefatos), o estudo da área do assentamento do sítio e a distribuição de ocorrência desses sítios (AZEVEDO NETTO et al., 2007).

Essa concepção supõe que a dimensão simbólica é um componente essencial da paisagem social. Mas não somente essa ideia nutre os estudiosos para um entendimento das práticas das movimentações populacionais, necessita-se de vários mecanismos para o entendimento do que se define como paisagem social (exemplo: as práticas/ações sociais; a ideia de território, espaço, lugar, identidade) e do que, também, deve ser levado em conta:

\begin{abstract}
La forma en que un lugar específico está construido y diseñado, así como los objetos que allí se encuentran, disparan ciertas acciones y generan ciertas relaciones y prácticas, mientras ignoran, inhiben o directamente clausuran ciertas otras. La cultura material y la espacialidad son al mismo tiempo constituidos y constituyentes. Se puede afirmar entoces que éstos no son simplemente el reflejo de la organización social, sino que activamente dan forma a la vida social (ACUTO, 2008, p. 167).
\end{abstract}

Nesse sentido, para uma compreensão do ambiente físico e a construção da imagem cartográfica, foram utilizados os estudos de Varnes (1974) que apresentam os critérios e níveis de informação para elaboração de uma carta de matriz geológica/ geomorfológica, e os estudos de Casseti (1981) que ajudam na concepção de conceitos de compartimentação de terreno. As pesquisas realizadas por Bevan e Lake (2013), Gupta e Devillers (2016) e Fairbairn (2017) contribuíram para discussão sobre a informação arqueológica no ambiente SIG (Sistema de Informação Geográfica) em um contexto espaço-temporal, como forma de compreensão do ambiente a partir da observação do relevo nos modos de ocupação do espaço.

Baseados nos estudos desenvolvidos por Silva (2000) e Longley et al. (2005), e nos estudos apresentados pelo IBGE (2009) buscamos os critérios conceituais e metodológicos para a elaboração e interpretação cartográfica, sendo eles a caracterização geológica, geomorfológica e dos solos, bem como os critérios de elaboração de SIG a partir da construção de banco de dados, escolha de atributos e execução de cartas temáticas.

\title{
LOCALIZAÇÃO DA ÁREA DE ESTUDO
}

O município de Camalaú - Paraíba - está localizado na área de abrangência da Região do Cariri Ocidental e Mesorregião da Borborema (Figura 1) e possui uma forte influência geográfica e climática, principalmente no que tange ao regime de precipitações. As implicações geológicas são, sobretudo, a formação dos solos saprolíticos (ESPINDOLA, 2017), de abrigos, matacões e afloramentos, onde estão os sítios cemitérios e painéis de pinturas.

A região possui um embasamento cristalino Neoproterozóico, com granitos e granodioritos, e Paleoproterozóico, pertencente ao Complexo Sertânia com gnaisse, metacarbonato e quartzito. Também, há a presença de uma Zona de Cisalhamento e duas faixas de Falhas Transcorrentes e o relevo é predominante suave ondulado, com vales estreitos e vertentes dissecadas (CPRM, 2002).

Os estudos de Martin e Ason, (2000), de Azevedo Netto et al. (2007) e de Matos (2015) mostram que a presença humana nessa área é evidente e existe há milênios com diversos grupos na região. Como assevera Martin (2008, p. 279), formam "pequenos grupos dependentes de uma fonte d'água que limitaria, também, o número de indivíduos e o entorno do seu 'habitat'".

Nesse sentido, Oliveira (2009, p.71) assegura que: 
A existência de diversas tribos dentro do Nordeste estabelece uma preocupação na formação das fronteiras culturais de cada uma das populações que viviam nesta região. Os próprios índios Cariri apresentavam-se dispersos em todo o território paraibano. É verdade que existiam lugares onde ocorriam uma maior concentração desta população, mas isto não os fazia se limitar apenas a estas regiões, podendo estar dispersos em outros locais, pois, muitas vezes, eles mudavam de local em busca de melhores condições de vida ou, muitas vezes, fugindo do próprio colonizador que se apossava dos locais onde estavam as aldeias destes povos.

Figura 1 - Localização do município Camalaú (no Estado da Paraíba) com a distribuição dos Sítios Arqueológicos. Fonte: NDIHR/UFPB. Autoria de Thiago Fonseca de Souza (2019).

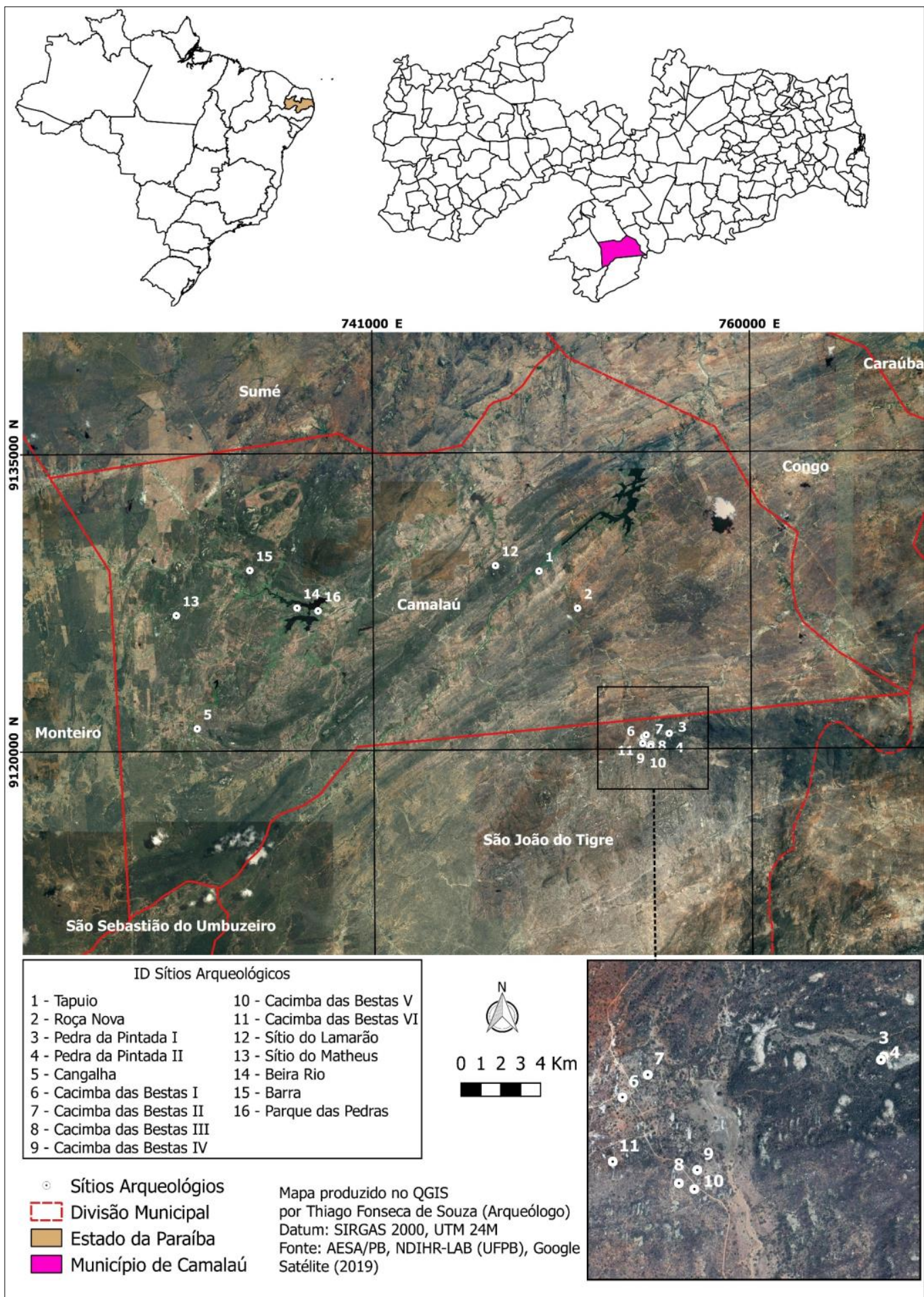


O termo Cariri recebeu essa denominação devido aos índios da nação Cariri, que viviam por quase toda a atual Mesorregião da Borborema desde tempos remotos até o contato com os colonizadores portugueses na segunda metade do século XVII. Cariri é um termo de origem tupi, com variação do Kiríri, e significa "silencioso", "deserto", "ermo" ou, pode significar também, "caatinga pouco áspera" (COSTA, 2003, p. 55). Os Cariris foram ocupando aquela área a partir da bacia do rio Paraíba e de seus afluentes, locais onde foi desenvolvida a cultura do algodão de fibras longas. As práticas agrícolas desses povos já demonstravam alterar o ambiente da fauna e flora locais, pois as queimadas eram comuns no cultivo da roça de mandioca ou milho (AZEVEDO NETTO et al., 2011, p. 272).

Segundo Neves (2010), a fundação do município começa a partir da doação de terras para a igreja católica, formando-se assim um povoado no ano de 1885 , no entanto, Camalaú só se torna município no ano de 1961, quando é desmembrado de Monteiro. O município ao Sul de Camalaú - São João do Tigre à época de 1800 a 1930 - era também distrito de Monteiro. Essa observação é relevante, já que alguns sítios arqueológicos, que estão situados em São João do Tigre (porção Nordeste, divisa com Camalaú) são considerados pela população como sendo localizados em Camalaú. Essa confusão se dá no momento da distribuição espacial pelo processo de história oral a população atual vê a localização dos sítios como sendo patrimônio camalauense.

\section{MATERIAIS E MÉTODOS}

A construção dessa pesquisa está pautada em 2 (dois) pilares metodológicos. $\mathrm{O}$ primeiro refere-se à elaboração cartográfica, e o segundo à pesquisa de campo. A elaboração cartográfica precede a etapa de pesquisa de campo, visto a necessidade de planejamento de campanhas nas quais buscamos sistematizar as informações que são relevantes à construção do documento cartográfico.

Para a elaboração cartográfica utilizamos o programa computacional QGis e o Grass para avaliação e elaboração dos modelos de canais de drenagem, classificação de formas de relevo, orientação de vertentes e cartas de declividade de terreno. Esses atributos auxiliam na análise da paisagem e na organização de dados físicos. As cartas temáticas de hipsometria e orientação de vertentes foram geradas a partir de dados SRTM 30x30 pixels, disponibilizada pelo DSR/INPE (Divisão de Sensoriamento Remoto/ Instituto Nacional de Pesquisas Espaciais). E a carta geológica foi executada pela CPRM (Companhia de Pesquisa e Recursos Minerais) e disponibilizada por meio eletrônico.

O limite municipal foi obtido no website do IBGE (Instituto Brasileiro de Geografia e Estatística) e importado para o QGis com a utilização da ferramenta vetor, podendo assim ser georreferenciado. Os pontos dos sítios arqueológicos foram obtidos através de GPS Garmin em campo, com a utilização do sistema de coordenadas UTM com Datum SIRGAS 2000 e inseridos sobre a carta georreferenciada. A carta hipsométrica foi gerada com a utilização do critério de fatiamento de altitudes, bem como as classes de 50 em 50 metros, tendo início em $\cong 400 \mathrm{~m}$ como altitude mais baixa e $\cong 800 \mathrm{~m}$ na altitude mais alta, obtidas pelo modelo SRTM. As cores para cada classe hipsométrica foram sugeridas pelo Manual de Cartografia do IBGE.

A partir dos critérios de canais de drenagem assegurados por Horton (1945 apud CHRISTOFOLETTI, 1980), foi gerada a carta de drenagem. Para a confecção da carta de orientação de vertentes utilizamos a ferramenta de aspecto para determinarmos a orientação geográfica delas, com critérios de fatiamento em Norte (N), Nordeste (NE), Leste (E), Sudeste (SE), Sul (S), Sudoeste (SW), Oeste (W) e Noroeste (NW), com a alternância de $45^{\circ}$ entre os pontos cardiais e colaterais. Os critérios de canais de drenagem de Horton deram base à confecção da carta de drenagem. Para a carta de 
imagem sombreada foi utilizada a ferramenta de sombreamento, resultando na imagem SRTM em cores de cinza, dando ênfase na fonte de iluminação com direção de $180^{\circ}$, visto que esse ângulo apresentou melhor resultado para avaliação, identificação e classificação das formas de relevo, apresentando maior acurácia na análise geomorfológica.

A carta de declividade, que é uma ferramenta de análise do ângulo das vertentes, foi gerada a partir dos dados da imagem SRTM e proporcionou a avaliação do relevo em classes de declividade, sugeridas pela EMBRAPA (SRTM 2005), onde são definidas 5 (cinco) classes: 0-3\% (plano), 3-8\% (suave ondulado), 8-20\% (ondulado), 20-45\% (forte ondulado) e 45-75\% (montanhoso). As tabelas de tabulação cruzada foram geradas utilizando a ferramenta com variáveis quantitativas e o software analisa dois ou mais planos de informação. Para esse trabalho, foram utilizados os planos de informação: orientação de vertentes e declividade do relevo; e planos hipsométricos e classes de declividade.

As análises da declividade das vertentes apresentam, na arqueologia, a perspectiva de que as localizações dos sítios arqueológicos seguem padrões em relação à rede hidrográfica, ou seja, pode-se observar que os sítios estão preferencialmente em áreas com menor declividade e, portanto, com maior acessibilidade ao recurso de água.

Quanto à pesquisa de campo, foram feitas campanhas de prospecção, sondagem e escavação, iniciando-se em 2005 com visitas ao município de Camalaú por conter sítios com pintura rupestre (ALMEIDA, 1979) naquela localidade. Selecionamos, portanto, os sítios de pintura rupestre, classificando os perfis gráficos em representações antropomórficas, zoomórficas e figuras geométricas. Nos painéis foram medidas sua largura e comprimento, bem como a orientação com o Norte magnético, as pinturas são preferencialmente na cor vermelha, porém foi observada a cor branca e a cor preta. Também, foram organizadas campanhas sistemáticas de prospecção e sondagem nas áreas onde havia ocorrência de pinturas, sendo então observada a presença de cerâmicas pré-históricas e líticos (lascas e lesmas em sua maioria), bem como a presença de seixos arredondados de quartzo em ambientes em que sua ocorrência não se faz natural, devido não ser área fonte ou de deposição desse material, e presença de fragmentos de óxido de ferro. Nos sítios de pintura não nos foi possível realizar as escavações, dado ao solo ser raso e com acréscimo de resistência à penetração. Trata-se, pois, de um solo autóctone, classificado como Neossolo e/ou solo saprolítico. Contudo, dois sítios apresentaram viabilidade de escavação, por serem sítios de sepultamento, localizados em topo de colina, sob abrigo de rocha.

A etapa da escavação foi efetivada em dois sítios de sepultamento: o sítio Barra e sítio Parque das Pedras, com escavações sistematizadas a partir da metodologia de escavação em nível artificial, sem a presença de perfil estratigráfico, visto que são solos saprolíticos, gerados pela decomposição de sua rocha matriz, com base nos seus caracteres litológicos. Ainda, considera-se o nível artificial devido a pouca profundidade da camada, cerca de 0,60m, e não haver alteração na estratigrafia natural. Em ambos os sítios a metodologia utilizada foi uma única, munidos de pincéis, trinchas e colheres, fomos retirando as camadas superiores até que os vestígios pudessem ser observados. A partir da exposição de um dado vestígio, este era então fotografado, desenhado em croquis e por fim coletado e catalogado.

No sítio Parque das Pedras já foi feita a exumação de esqueletos parcialmente completos, de maneira que o procedimento de escavação e de coleta foram um pouco diferentes, ou seja, expunha-se o esqueleto o máximo possível, obtendo as coordenadas (x, y e z), orientação de decúbito, vestígios relacionados e coleta de sedimento no crânio. Entre as costelas (para análises químicas), era feito o croquis, as fotografias e, por fim, coletava-se o esqueleto e o acondicionava envolto em papel alumínio, filme plástico e 
plástico bolha, organizando-o para transporte em uma caixa térmica, sendo todo material catalogado.

\section{DESCRIÇÃO DOS SÍTIOS ARQUEOLÓGICOS EM CAMALAÚ - PB:}

\section{RESULTADOS E ANÁLISES}

Em Camalaú foram registrados até o momento 16 sítios arqueológicos classificados por sua materialidade, tanto na natureza quanto na modalidade dos vestígios encontrados

Quadro1 - Classificação e localização dos sítios arqueológicos em Camalaú - PB. Fonte: Projeto Os Agenciamentos Semióticos na Construção dos Painéis Rupestres: A dinâmica entre os grafismos reconhecíveis e puros, no Cariri Ocidental Paraibano (2018), NDIHR/UFPB.

\begin{tabular}{|c|c|c|c|c|}
\hline \multirow{2}{*}{ Sítio } & \multicolumn{2}{|c|}{ Materialidade } & \multicolumn{2}{|c|}{ Localização (Zona 24M) } \\
\hline & Natureza & Modalidade & UTM E & UTM N \\
\hline Barra & Sepultamento & $\begin{array}{l}\text { Ósseo Humano e } \\
\text { cerâmica }\end{array}$ & 734801 & 9129111 \\
\hline Beira Rio & Registro Rupestre & Pintura & 737170 & 9127203 \\
\hline Cacimba das Bestas I & Registro Rupestre & Pintura & 754572 & 9120600 \\
\hline Cacimba das Bestas II & Registro Rupestre & Pintura & 754698 & 9120711 \\
\hline Cacimba das Bestas III & Registro Rupestre & Pintura & 754849 & 9120172 \\
\hline Cacimba das Bestas IV & Registro Rupestre & Pintura & 754940 & 9120237 \\
\hline Cacimba das Bestas V & $\begin{array}{l}\text { Registro Rupestre e } \\
\text { Cerâmica }\end{array}$ & Pintura e Cerâmica & 754925 & 9120142 \\
\hline Cacimba das Bestas VI & $\begin{array}{c}\text { Registro Rupestre e } \\
\text { Cerâmica }\end{array}$ & Pintura e Cerâmica & 754522 & 9120281 \\
\hline Cangalha & Registro Rupestre & Pintura & 732118 & 9121133 \\
\hline Lamarão & Registro Rupestre & $\begin{array}{l}\text { Registro Rupestre, } \\
\text { Cerâmica e Lítico }\end{array}$ & 747164 & 9129297 \\
\hline Matheus & $\begin{array}{c}\text { Registro Rupestre e } \\
\text { possível Sepultamento }\end{array}$ & $\begin{array}{c}\text { Pintura e Ósseo } \\
\text { Humano }\end{array}$ & 731094 & 9126853 \\
\hline Parque das Pedras & Sepultamento & $\begin{array}{l}\text { Ósseo Humano, } \\
\text { Cerâmica e Lítico }\end{array}$ & 738228 & 9127050 \\
\hline Pedra da Pintada I & Registro Rupestre & Pintura e Gravura & 755866 & 9120796 \\
\hline Pedra da Pintada II & Registro Rupestre & Pintura & 755852 & 9120779 \\
\hline Roça Nova & Registro Rupestre & Pintura & 751284 & 9127122 \\
\hline Tapuio & $\begin{array}{c}\text { Registro Rupestre e } \\
\text { Cerâmica }\end{array}$ & Cerâmica e Lítico & 749354 & 9129008 \\
\hline
\end{tabular}

Os sítios arqueológicos em Camalaú estão dispostos em afloramentos rochosos e matacões, ou em seu entorno próximo, o que significa dizer que foram executadas sondagens tendo sido localizados vestígios de modalidades líticas, cerâmicas, registros rupestres e ossos humanos. As pinturas são majoritariamente na cor vermelha com motivos de antropomorfos, zoomorfos, representações de objetos e, ainda, registros em gravuras (MATOS, 2015).

Um aspecto geológico que é importante compreender para a análise dos sítios arqueológicos de sepultamento são as formações rochosas que dão origem aos abrigos. Os abrigos de rocha são formações naturais e podem ser formados por afloramentos 
rochosos, mas também como blocos basculhados e superpostos formando cavidades. Os afloramentos são ocasionados por processos naturais ${ }^{1}$ de erosão do solo ou escorregamentos e deslizamentos da camada superficial, permitindo que haja a exposição da rocha, ou ainda, quando esse afloramento possui um ângulo agudo forma-se o abrigo sob rocha. Outra tipologia de formação de abrigo sob rocha é o basculamento de rochas ocasionando uma cavidade, esse basculamento se dá a partir da reorganização de blocos rolados ou erodidos com dimensões que variam entre $64 \mathrm{~mm}$ a mais de $256 \mathrm{~mm}$, ou seja, com tamanhos de seixos, pedregulhos e matacões.

Portanto, os abrigos possuem um espaço aberto onde grupos pré-coloniais ocupavam e faziam usos diversos, visto que vestígios arqueológicos (Figura 2) são comumente encontrados, tais como, cerâmica, pinturas, líticos e sepultamentos (SOUZA, 1997).

Figura 2 - Vestígios encontrados nos sítios arqueológicos:

2a) Cestaria em sepultamento, sítio Barra (Foto de Carlos Xavier, 2008);

2b) Sepultamento primário de indivíduo, sítio Parque das Pedras (Foto de Carlos Xavier, 2008);

2c) Peça lítica em superfície, sítio Lamarão (Foto de Carlos Xavier, 2008);

2d) Peças cerâmicas em superfície, sítio Tapuio (foto de Carlos Xavier, 2012).

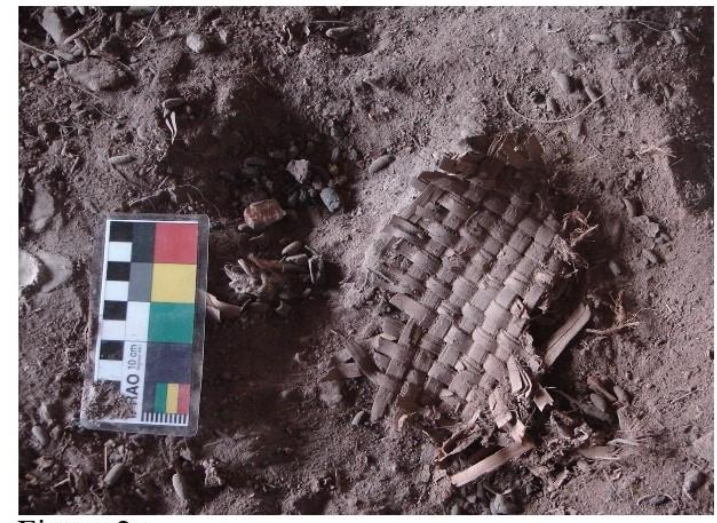

Figura 2a

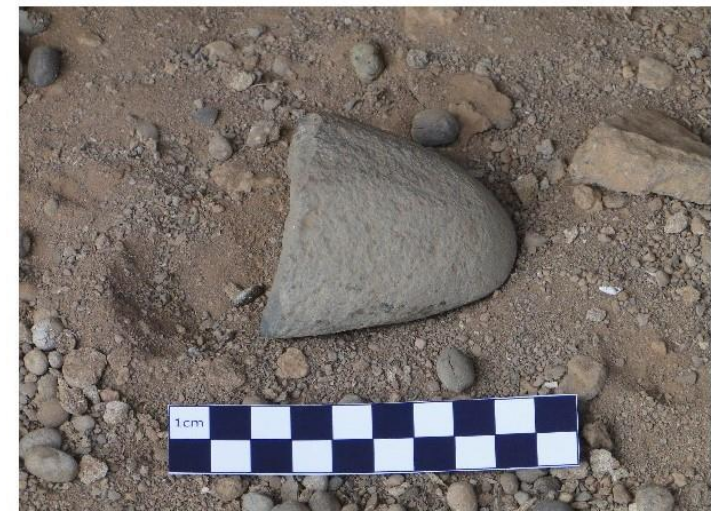

Figura 2c

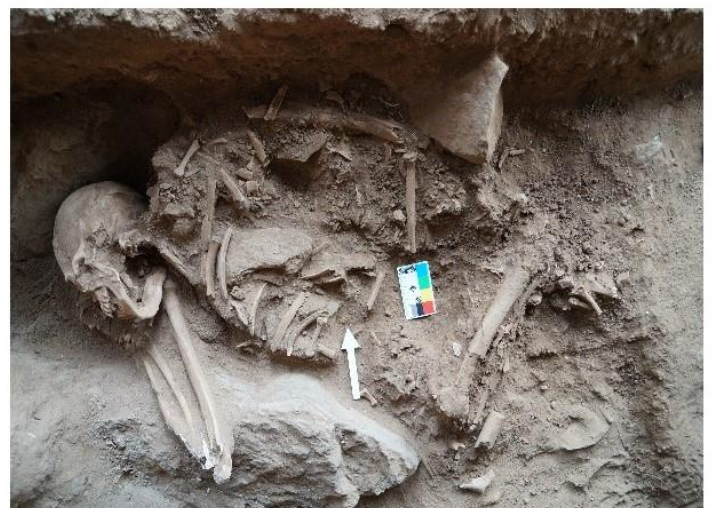

Figura $2 b$

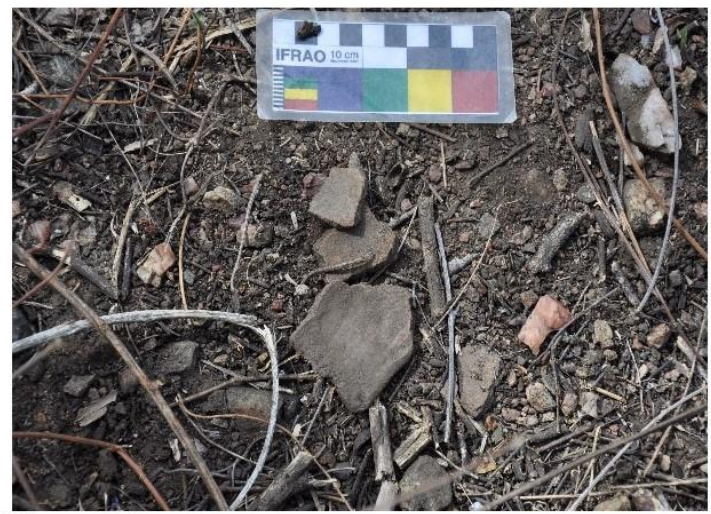

Figura 2d

Portanto, a área estudada está inserida na unidade de paisagem proposta por Tricart (1977) em seu trabalho sobre Ecodinâmica. Nele, o autor classifica essas paisagens como instáveis, ou seja, como ambientes onde predomina a morfogênese, ambientes em que o

\footnotetext{
${ }^{1}$ Há também afloramentos de ação antrópica, vistos principalmente em cortes e taludes, no entanto, esse trabalho se atém aos afloramentos naturais.
} 
transporte do material (solo) é considerado rápido, devido à baixa concentração vegetal, solos rasos, vertentes com forte processo de dissecação e alta concentração pluvial.

$\mathrm{Na}$ Figura 3, apresenta-se a carta hipsométrica e a rede de drenagem com a distribuição espacial dos sítios. Observa-se um relevo com altitudes variando entre 490 $\mathrm{m}$ e $740 \mathrm{~m}$. Os sítios estão em sua maioria localizados na faixa de $550 \mathrm{~m}$ e $650 \mathrm{~m}$ de altitude, ou seja, predomina uma ocupação maior nas áreas de altitude média. Portanto, se afirma que há uma dispersão dos pontos onde estão situados os sítios, ainda que fujam a essa premissa os sítios Cacimba das Bestas e Pedra Pintada, que estão em uma altitude de $650 \mathrm{~m}$. A drenagem da área compreendida pelos sítios arqueológicos está inserida nos domínios da bacia hidrográfica do rio Paraíba, já a drenagem no município segue um padrão dendrítico, com cursos d'água intermitentes.

Figura 3 - Carta hipsométrica e drenagem.

Fonte: NDIHR/UFPB. Autoria de Thiago Fonseca de Souza (2019).

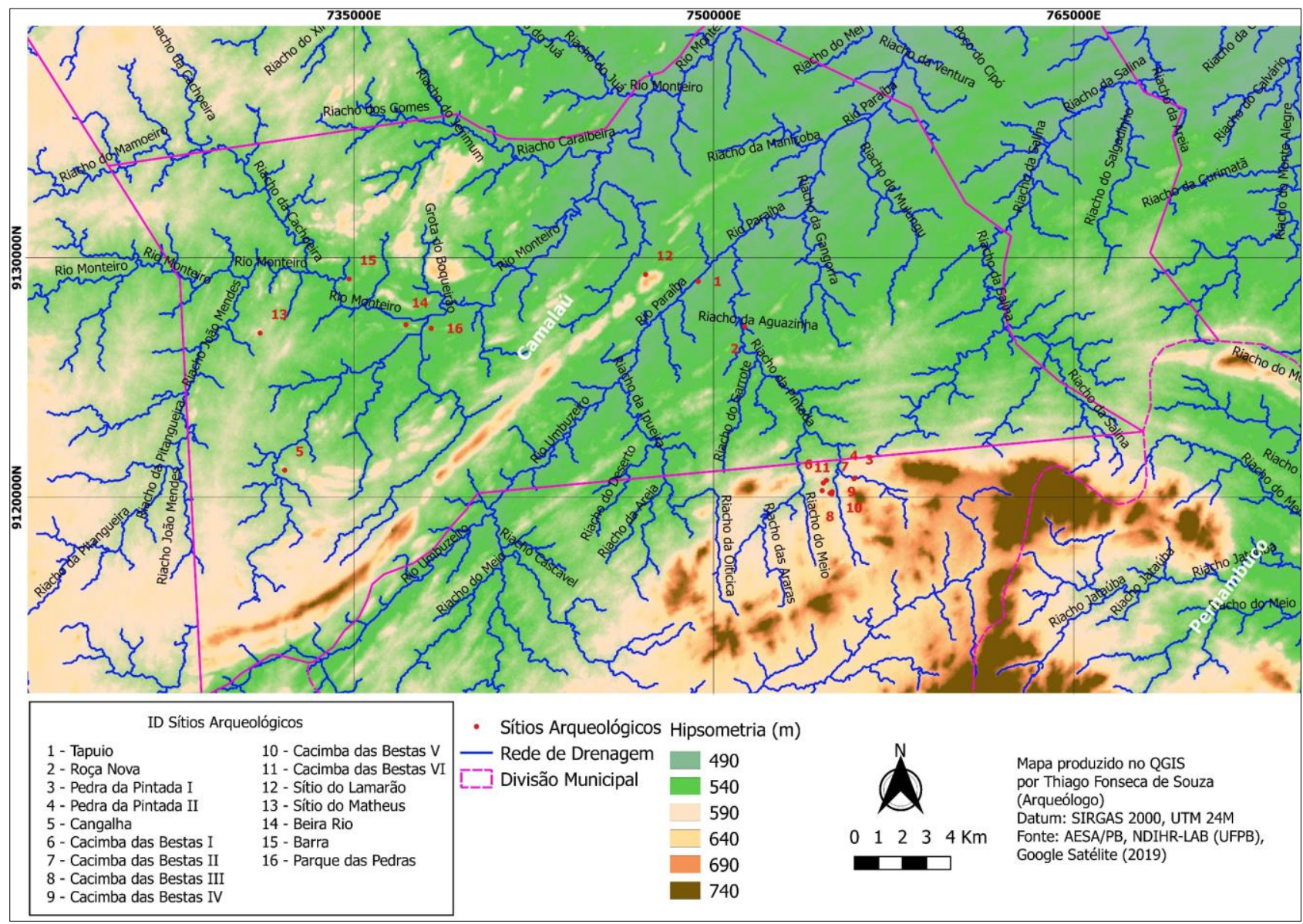

Por ser uma área com solos rasos e com pedregulhosos, muitos canais de escoamento superficial são formados nos períodos de chuva, ocasionando processos erosivos a partir de sulcos nas áreas com solo mais espesso (entre 0,10 $\mathrm{m}$ até 1,00 $\mathrm{m}$ de profundidade) e, também, erosão laminar. Esse tipo de erosão ocasiona a exposição da rocha, devido às camadas menos espessas de solo (até $0,25 \mathrm{~m}$ ) e estão em áreas com declividade forte ondulada (entre 20 a 45\% de declividade da vertente), visto que não há infiltração no solo. Ou, quando há infiltração, essa é com baixa taxa de infiltrabilidade devido à baixa espessura de solo.

Os sítios arqueológicos até o momento podem ser divididos em duas categorias de localização geológica (Figura 4): 1) blocos (com mais de $2 \mathrm{~m}$ de altura) aflorantes que 
servem como painéis para os registros rupestres (Figura 2a e 2b); e 2) abrigos em matacões basculhados onde se inserem os cemitérios, considerados abrigos de rocha (Figura 2c e 2d).

Figura 4 - 4a e 4b) Afloramentos com painéis com registros de pinturas (sítio Roça Nova); 4c e 4d) Abrigo sob rochas basculadas com pinturas rupestres e possível ocupação por enterramentos (Sítio do Matheus) e sítio com sepultamento (sítio Parque das Pedras). Fotos 4a, 4b e 4c de Carlos Xavier (2013). Foto 4d de Thiago Fonseca (2018).

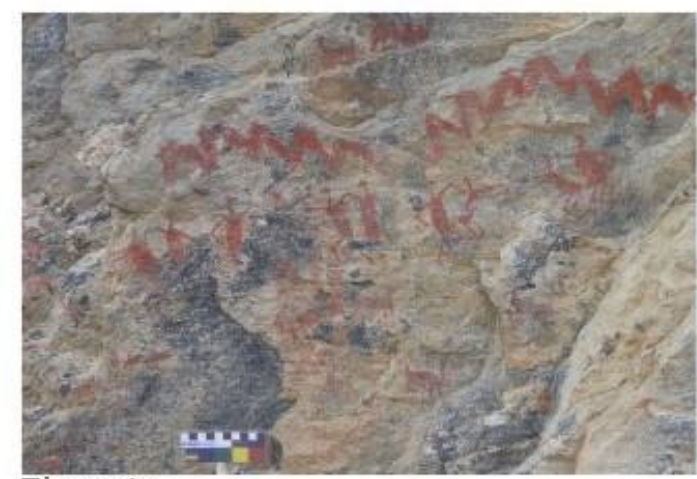

Figura $4 \mathrm{a}$

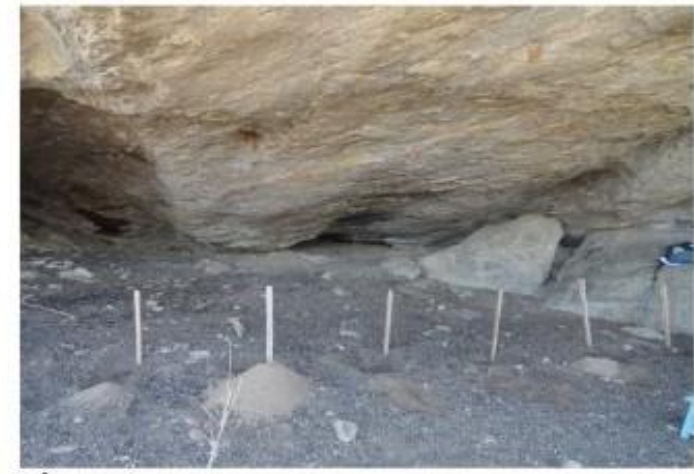

Figura $4 \mathrm{c}$

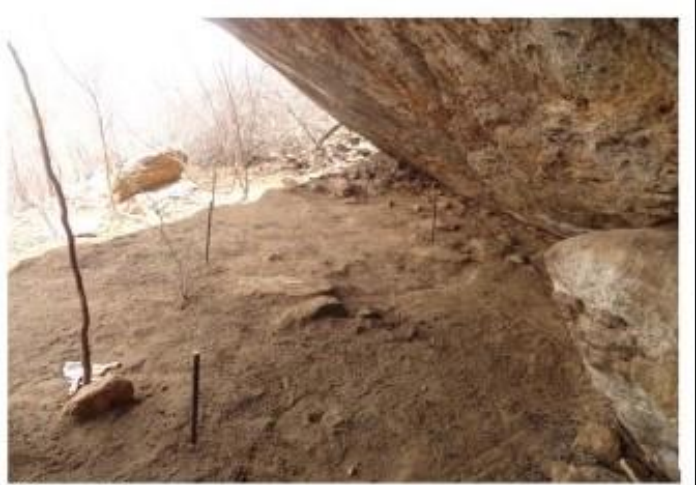

Figura $4 b$

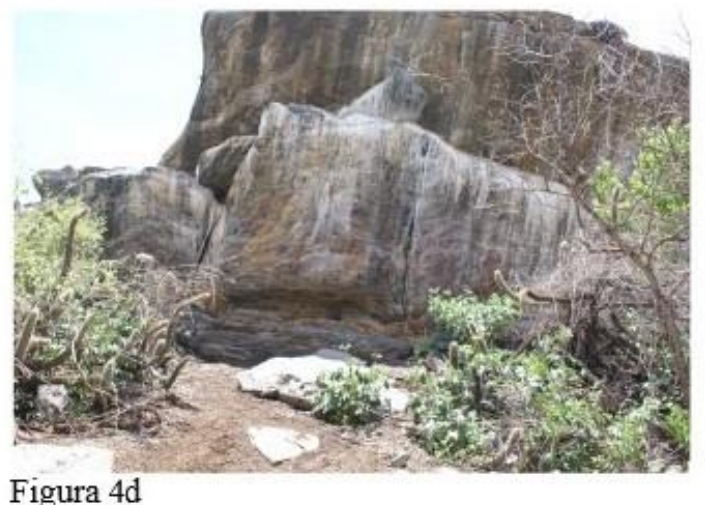

É possível afirmar que os processos tanto de intemperismo físico, químico e biológico, quanto geomorfológicos são elementos de transformação do espaço de ocupação humana, de maneira que as evidências estudadas estão intrinsecamente vinculadas à formação geológica de granitos e gnaisses. E, sob esse aspecto, observa-se que há uma predominância pela ocupação em relevos inclinados (vertentes) onde os processos de erosão criaram os abrigos e afloramentos, ou seja, por serem objetos de processos erosivos, a vertente é a faceta com maior vulnerabilidade gravitacional.

São apresentados (Quadro 2) os sítios em relação as orientações das vertentes. Trata-se da exposição da superfície do terreno, que condiciona a direção da variação da declividade, influenciadas, portanto, pelas dinâmicas de meteorização ligadas à insolação, chuva e erosão eólica, sendo que na avaliação dos assentamentos observa-se essa declividade como indicador de mobilidade dos grupos na captação de água, proteção de chuvas e contra a exposição à insolação.

Foi possível verificar a posição dos sítios a partir da classe de declividade (Figura 5), onde o relevo se apresenta suavemente ondulado (correspondendo a aproximadamente 49\% da área total), com topos fortemente ondulados e uma área orientada para Sudeste com oposição em Noroeste, formalizando topos inclinados, corroborando com a drenagem em flexão SE - NW. Esses dados evidenciam um terreno plano na base, e suave ondulado nas bordas da vertente, com vertentes fortemente onduladas, corroborando a 
teoria dos vales encaixados e entalhamento de drenagem. Ao observar a localização macro dos assentamentos, afirma-se que sua disposição principal no terreno está na classe suave ondulado (3\% a $8 \%$ de declividade), sendo eles: Tapuio, Cacimba das Bestas I, Cacimba das Bestas II, Cacimba das Bestas III, Cacimba das Bestas IV, Cacimba das Bestas V e Cacimba das Bestas VI em uma observação mais detalhada da área dos sítios suas declividades. Os sítios Roça Nova e Cangalha estão dispostos sobre declividades de $8 \%$ a 20\%, já os sítios Pedra da Pintada I e Pedra da Pintada II aferem-se que estão dispostos sobre declividades de $20 \%$ a $45 \%$. Os sítios Lamarão, Matheus, Beira Rio, Barra e Parque das Pedras estão dispostos sobre declividades de $45 \%$ a $75 \%$.

Quadro 2 - Distribuição dos sítios arqueológicos em função geomorfológica da orientação de vertentes e altitudes. Fonte: NDIHR/UFPB, dados das pesquisas (2018).

\begin{tabular}{ccc}
\hline Sítio & Orientação & Altitude \\
\hline Barra & Norte & $\approx 560 \mathrm{~m}$ \\
\hline Beira Rio & Nordeste & $\approx 560 \mathrm{~m}$ \\
\hline Cacimba das Bestas I & Nordeste & $\approx 560 \mathrm{~m}$ \\
\hline Cacimba das Bestas II & Norte & $\approx 590 \mathrm{~m}$ \\
\hline Cacimba das Bestas IV & Norte & $\approx 590 \mathrm{~m}$ \\
\hline Cacimba das Bestas V & Norte & $\approx 590 \mathrm{~m}$ \\
\hline Cacimba das Bestas VI & Norte & $\approx 550 \mathrm{~m}$ \\
\hline Cangalha & Nordeste & $\approx 590 \mathrm{~m}$ \\
\hline Lamarão & Nordeste & $\approx 590 \mathrm{~m}$ \\
\hline Mateus & Leste & $\approx 580 \mathrm{~m}$ \\
\hline Parque das Pedras & Norte & $\approx 460 \mathrm{~m}$ \\
\hline Pedra da Pintada I & Nordeste & $\approx 590 \mathrm{~m}$ \\
\hline Pedra da Pintada II & Nordeste & $\approx 590 \mathrm{~m}$ \\
\hline Roça Nova & Noroeste & $\approx 520 \mathrm{~m}$ \\
\hline Tapuio & Nordeste & $\approx 500 \mathrm{~m}$ \\
\hline
\end{tabular}

Em relação a geologia (Figura 6), observa-se que oito sítios (todos com registros rupestres) estão localizados na Suíte Calcialcalina de Médio a Alto K Itaporanda, apresentando rochas granitas e granodiorito porfirítico associadas a diorito. Outros oito sítios (três com presença de ossos humanos, sendo dois desses com sepultamento; e cinco com presença de registros rupestres) estão localizados no Complexo Sertânia contendo rochas como gnaisse, metacarbonato, quartzito e metavulcânica máfica. 
Figura 5 - Carta de orientação de vertentes.

Fonte: NDIHR/UFPB. Autoria de Thiago Fonseca de Souza (2019).

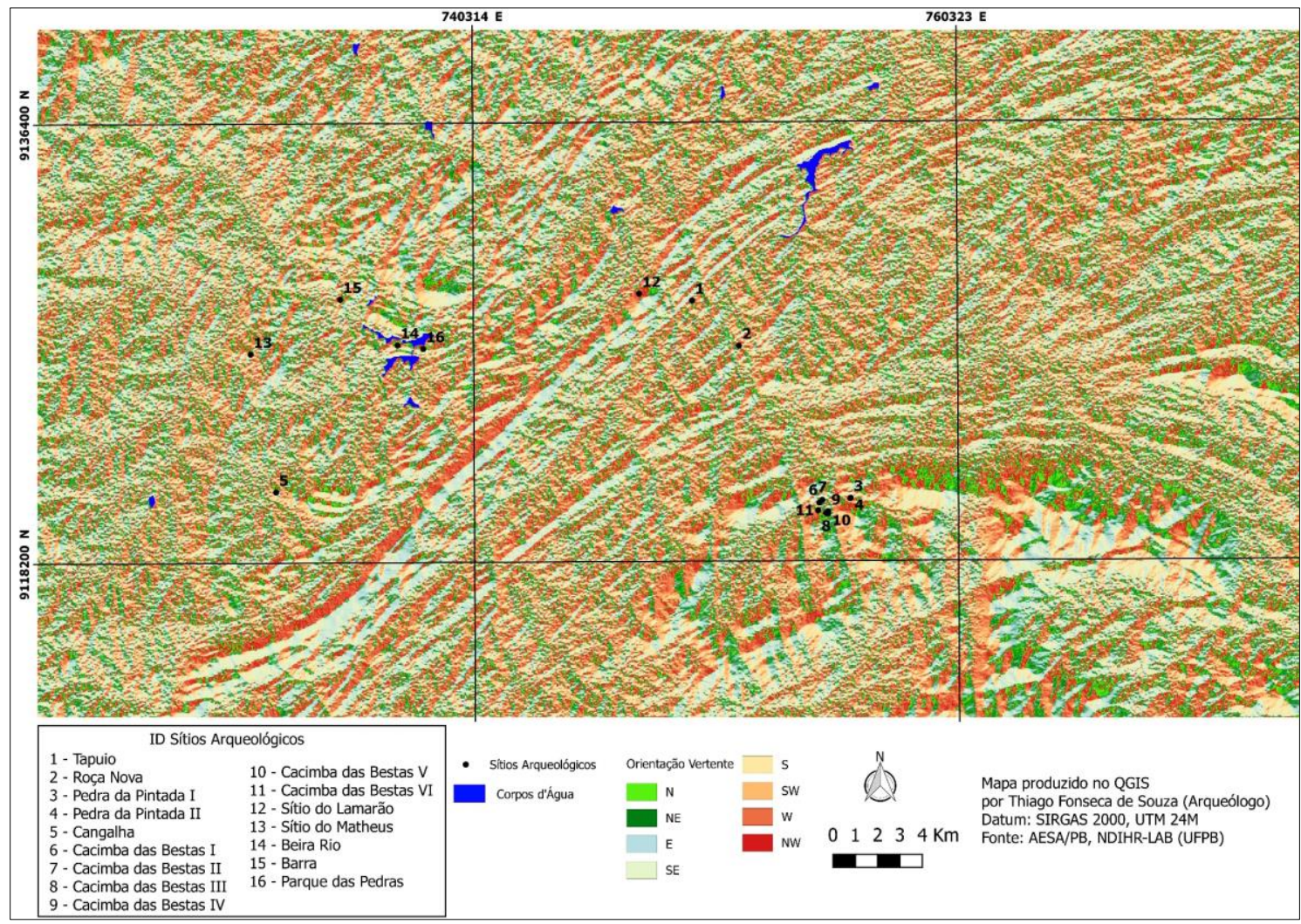

Figura 6 - Carta geológica (Litoestratigráficos).

Fonte: NDIHR/UFPB. Autoria de Thiago Fonseca de Souza (2019).

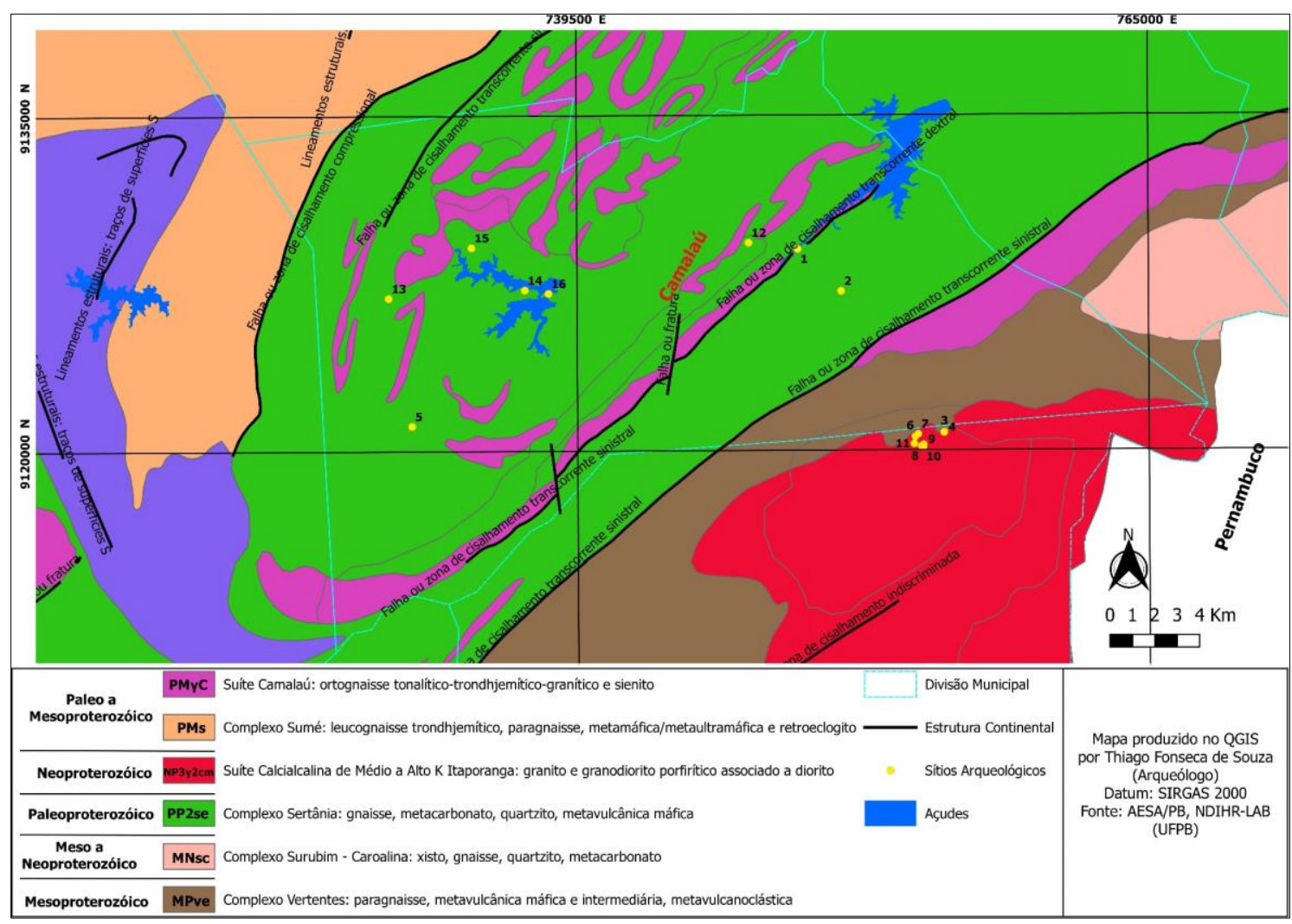




\section{CONSIDERAÇÕES FINAIS}

A ocupação dos sítios nesse espaço tem como característica a proximidade de canais de escoamento. Contudo, a presença dos sítios não está vinculada aos canais principais, nem tão pouco às cabeceiras, e sim aos canais de $3^{\text {a }}$ e $4^{\mathrm{a}}$ ordem (segundo a classificação de Horton). Esse aspecto é justificado pelo regime climático na região, onde a concentração pluvial se dá em poucos meses, ocasionando grandes cheias. Também pelo rastejo de material de solo, implicando em processos erosivos e transbordamento dos canais de drenagem. Os canais de drenagem de $1^{\text {a }}$ ordem são de alta energia hídrica, observado pelos registros erosivos, o que implica na dificuldade de ocupação. E, ainda, quanto à drenagem, não foram localizados sítios nas proximidades da área de enchente.

A localização dos sítios com sepultamento tem predominância na direção geográfica Norte e Nordeste, sendo abrigos de afloramentos caracterizados por uma estratigrafia homogênea (tanto em granulometria quanto em coloração) originada da rocha matriz. Outro aspecto percebido é na distribuição dos sítios de sepultamento (Barra, Parque das Pedras), que estão situados próximos em um complexo de serras, relacionado às redes de drenagens do rio Monteiro e localizados nos pontos mais elevados na região. Portanto, esses lugares apresentam restrição social dos grupos atrelados às atividades de sepultamento.

A geomorfologia do município é formada por um relevo sinuoso ondulado ( $8-20 \%)$ e forte ondulado $(20-45 \%)$ formando os morros e serrotes. Treze sítios arqueológicos estão em altitudes variando entre $550 \mathrm{~m}$ e $590 \mathrm{~m}$, e 1 (um) sítio a $460 \mathrm{~m}$ de altitude, 1 (um) em $500 \mathrm{~m}$ e 1 (um) em $520 \mathrm{~m}$.

Por fim, na análise dos estudos geoarqueológicos dos sítios, tendo como base as distribuições geoambientais, percebe-se que houve estratégias de ocupações distintas para as práticas culturais expressas em locais particulare, onde as questões ambientais prevalecentes se destacam em cotas altimétricas mais elevadas, posição preferencial em relação ao Norte magnético. Esse entendimento representa o princípio de compreensão dos padrões e estratégias de ocupações destas populações pré-históricas nos Cariris Velhos. 


\section{REFERÊNCIAS BIBLIOGRÁFICAS}

AB'SABER, Aziz. N. Geomorfologia. Geomorfologia, Série especial. Instituto de Geografia, São Paulo, 1969.

ACUTO, Félix A. Materialidad, espacialidad y vida social. Reinterpretando el Período Prehispánico Tardío de los Andes del Sur. In ACUTO, F.A; ZARANKIN, A. (ed.). En Sed Non Satiata II. Acercamientos sociales en la arqueología latinoamericana. 2008. P. 159-193.

ALMEIDA, Ruth Trindade de. A arte rupestre nos Cariris Velhos. João Pessoa: Universitária/UFPB. 1979.

ANGELUCCI, Diego E. A partir da terra: a contribuição da geoarqueologia. In: MATEUS, M. MORENO-GARCÍA (Eds.). Paleoecologia Humana e Arqueociências. Um programa multidisciplinar para a Arqueologia sob a tutela da cultura. Trabalhos de Arqueologia, 29, IPA, Lisboa. 2003.

AZEVEDO NETTO, Carlos X; KRAISCH Adriana M. P. de O.; ROSA, Conrad R. Territorialidade e arte rupestre - inferências iniciais acerca da distribuição espacial dos sítios de arte rupestre na região do Cariri paraibano. Revista de Arqueologia. 2007, 20:51-65.

AZEVEDO NETTO, Carlos X., DUARTE, Patrícia; OlIVEIRA, Adriana M. P. de. Uma visão arqueológica da relação entre cultura e ambiente: a inserção ambiental dos sítios arqueológicos do município de São João do Cariri, Paraíba. Ñanduty, Dourados, 2012. 1:116-129.

AZEVEDO NETTO, Carlos X., ROSA, Conrad R.; MIRANDA, Pablo G. de. Semiótica dos sítios cerâmicos da Região do Cariri Ocidental - PB. CLIO, Série Arqueológica, Recife, 2011. 2:265288.

BEVAN, Andrew; LAKE, Mark. Computational approaches to archeological spaces. University College London Institute of Archaelogy Publications: Computational Approaches to Archaeological Spaces. Walnut Creek, CA, USA. 2013.

BINFORD, Lewis R. Archeological systematics and the study of culture process. American Antiquity, v. 31, n. 1, 1965. 203-210.

BRITO NEVES, B. DE ; SCHMUS, W. R. VAN; SANTOS, E.J. DOS; CAMPOS NETO, M. C.; KOZUCH, M. O evento Carirís Velhos na província Borborema: Integração de dados, implicações e perspectivas, Revista Brasileira de Geociências, 1995. 25(4):279-296.

BUTZER, Karl W. Challenges for a cross-disciplinary geoarchaeology: the intersection between environmental history and geomorphology. Geomorphology, 101, 2008. 402-411.

CASSETI, Valter. Sugestões para a compartimentação do relevo através do tratamento gráfico da informação. Boletim Goiano de Geografia. v. 1, n. 2, 1981. 54-67.

CASSIRER, Ernst. Antropologia filosófica. 2.ed. Tradução de Vicente Félix Queiroz. São Paulo: Mestre Jou. 1977.

CHRISTOFOLETTI, Antonio. Geomorfologia. São Paulo: Edgard Blücher, 1980.

COSTA, José J. D. Impactos Socioambientais das Políticas de Combate à Seca na Paraíba. Tese de Doutorado. São Paulo, Universidade de São Paulo. 2003.

CORREA, Antonio C. de B.; SILVA, Danielle G. Análise geomorfológica e morfoestratigráfica dos modelados deposicionais da área de Conceição das Crioulas, Salgueiro - PE: um subsídio para a reconstrução paleoambiental. Clio Arqueológica, v. 2, n. 19, 2005. p. 05-29.

CPRM - Serviço Geológico do Brasil. Projeto cadastro de fontes de abastecimento por água subterrânea. Diagnóstico do município de Camalaú, estado da Paraíba. Recife, CPRM/ PRODEEM. 2005. 22p.

DEL LAMA, Eliane A. Geologia e herança cultural. Revista Brasileira de Geociências, 2006. 2:379 381. 
ESPINDOLA, Carlos R. Material de origem do solo. Revista do Instituto Geológico, São Paulo, 38(1), 2017. p. 59-70.

FAIRBAIRN, David. The effectiveness of cartographic visualisations in landscape archeology. Proceedings of the International Cartographic Association, 2017.

GOLDBERG, Paul; MEIGNEN, Liliane; MALLOL, Carolina. Geoarchaeology, site formation and transitions. In: SHEA, J. J.; LIEBERMAN, D.F. (ed.). Transitions in prehistory: essas in honor of Ofer Bar-Yousef., 2009.

GUPTA, Neha; DEVILLERS, Rodolphe. Geographic visualization in archeology. Journal Archeological Method Theory. 2017. 24: 858-885.

HONORATO, Laina da C. Arqueologia da paisagem e geoarqueologia: experiências em projetos de pesquisa. TOPOS, 2009. 1:127 - 147.

HORTON, Robert E., Erosional development of streams and their drainage basin: hidrographical approach to quantitative morphology. Geological Society of American Bulletin, Colorado, v.56, n.3, 1945.p. 275-370.

IBGE - Instituto Brasileiro de Geografia Estatística. Manual técnico de geomorfologia. IBGE, Rio de Janeiro, RJ, 2009.

INGOLD, Tim. Estar vivo - Ensaios sobre movimento, conhecimento e descrição, Petrópolis, Vozes. 2011.

INGOLD, Tim. Trazendo as coisas de volta à vida: emaranhados criativos num mundo de materiais, in Horizontes Antropológicos, Porto Alegre, 2012. 37:25-44.

ISNARDIS, Andre; LINKE, Vanessa. Pedras pintadas, paisagens construídas: a integração de elementos culturalmente arquitetados na transformação e manutenção da paisagem. Revista de Arqueologia, São Paulo, 2010. 1:41-58.

LONGLEY, Paul A.; GOODCHILD, Michael F.; MAGUIRE, David J.; RHIND, David W. Geographical Information Systems and Science. 2nd Edition, John Wiley \& Sons Ltd. 2005.

LUCENA, Veleda. A ocupação humana e os processos deposicionais. Clio, n. 3. 1986. p. 169-175.

MABESOONE, J. M; LOBO, Helia R. C. Paleosols as stratrigaphic indicators for the Cenozoic history of Northeastern Brazil. Catena, v. 7, 1980. 67-78.

MAIA, Rubson P.; BEZERRA, Francisco H. R. Condicionamento estrutural do relevo no Nordeste Setentrional Brasileiro. Mercartor, v. 13, n. 1, Fortaleza, 2014. 127-141.

MARTIN, Gabriela. Pré-História do Nordeste do Brasil. 5aed. Recife: Universitária/UFPE. 2008.

MARTIN, Gabriela; ASON, Irma. A tradição Nordeste na arte rupestre do Brasil. Clio Arqueológica. n. 14, 2000. 99-109.

MATOS, Francisco de Assis Soares de. Os antropomorfos no registro rupestre do semiárido paraibano: caracterização das representações na Microrregião do Cariri Ocidental / Francisco de Assis Soares de Matos. - Recife, 2015. 187 f.: il. ; $30 \mathrm{~cm}$.

MORAIS, Jose L. de. Tópicos de arqueologia da paisagem. Revista do Museu de Arqueologia e Etnologia, São Paulo, 2000. 10:3 - 30.

NEVES, Cristiane M. Um olhar para o Município de Camalaú: Potencialidades Turísticas no Cariri Paraibano. 2010. Monografia (Graduação), Geografia, Universidade Federal da Paraíba UFPB), João Pessoa. 2010.

OLIVEIRA, Adriana M. P. de. Entre a pré-história e a história: em busca de uma cultura histórica sobre os primeiros habitantes do Cariri Paraibano. Dissertação de Mestrado. João Pessoa, Universidade Federal da Paraíba. 2009. 
PEUVAST, Jean-Pierre; SALES, Vanda Claudino. Aplainamento e geodinâmica: revisitando um problema clássico em geomorfologia. Mercator - Revista de Geografia da UFC, ano1, n. 1, 2002. $1-38$.

RUBIN, Julio Cezar Rubin de; SILVA, Rosiclér T. Arqueologia, dinâmica das vertentes e perdas de solo. Revista do Museu de Arqueologia e Etnologia, São Paulo, 14, 2004. 179-193.

SANTOS, Adelson. Geomorfologia na pesquisa arqueológica. Clio Série Arqueológica. n. 12, 1997. 205-214.

SILVA, Jorge X. da. Geomorfologia, análise ambiental e geoprocessamento. Revista Brasileira de Geomorfologia, v. 1, n. 1, 2000. 48-58.

SOUZA, Alfredo M.. Dicionário de arqueologia. ADESA, Rio de Janeiro. 1997.

SOUZA, Thiago Fonseca de. Espaço e Apropriação Cultural - As Paisagens dos Sítios Arqueológicos de Camalaú, PB. Monografia (Licenciatura Plena em História), Departamento de História, Universidade Federal da Paraíba, João Pessoa. 2013.

SOUZA, Thiago Fonseca de. Pinturas rupestres e paisagem: um estudo de caso das representações zoomórficas do Vale do Catimbau - PE. Dissertação de Mestrado. Recife, Universidade Federal de Pernambuco. 2016.

SUGUIO, Kenitiro. A importância da geomorfologia em geociências e áreas afins. Revista Brasileira de Geomorfologia, v. 1, n. 1. 2000. p. 80-87.

STEIN, Julie K. A review of site formation processes and their relevance to geoarcheology. In: GOLDENBERG, P.; HOLLIDAY, V.T.; FERRING, C. R. (org.). Earth sciences and archeology. Kluwer Academic/ Plenum Publishers. 2001.

TRICART, Jean. Ecodinâmica. IBGE, Rio de Janeiro. Diretoria Técnica, 1977.

VARNES, David J. The logic of geological maps, with reference to their interpretation and use for engineering purposes. U.S. Geological Survey Professional Paper, 837, 1974. 